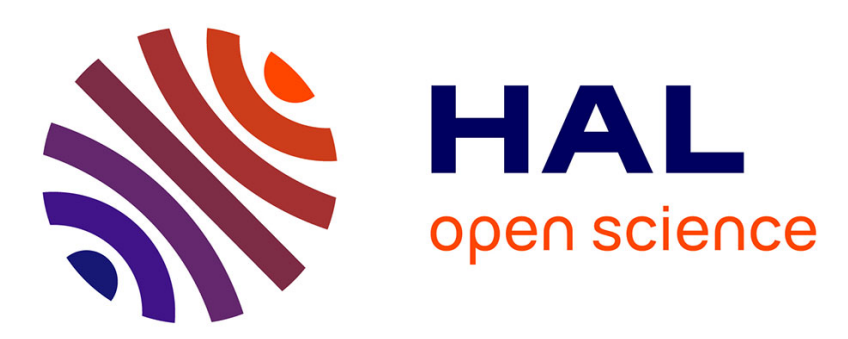

\title{
Estimating $\pi$ binding energy of N-Heterocyclic carbenes: The role of polarization
}

\author{
Elixabete Rezabal, Gilles Frison
}

\section{To cite this version:}

Elixabete Rezabal, Gilles Frison. Estimating $\pi$ binding energy of N-Heterocyclic carbenes: The role of polarization. Journal of Computational Chemistry, 2015, 36, pp.564-572. 10.1002/jcc.23852 . hal01120413

\section{HAL Id: hal-01120413 \\ https://hal.science/hal-01120413}

Submitted on 25 Feb 2015

HAL is a multi-disciplinary open access archive for the deposit and dissemination of scientific research documents, whether they are published or not. The documents may come from teaching and research institutions in France or abroad, or from public or private research centers.
L'archive ouverte pluridisciplinaire HAL, est destinée au dépôt et à la diffusion de documents scientifiques de niveau recherche, publiés ou non, émanant des établissements d'enseignement et de recherche français ou étrangers, des laboratoires publics ou privés. 


\title{
Estimating $\pi$ binding energy of N-heterocyclic carbenes: the role of polarisation
}

\author{
Elixabete Rezabal, Gilles Frison ${ }^{\dagger}$
}

\begin{abstract}
In this work, the tuneability of the $\pi$ acceptor or donor properties of a set of N-heterocyclic carbenes (NHCs) with a wide spectrum of electronic characteristics is established by means of density functional theory (DFT) and energy decomposition analysis (EDA) tools. Even though the main orbital interaction contribution to the NHC coordination is the $\sigma$ donation, a significant contribution of the $\pi$ interactions to the bond is observed. By means of carefully selected coordination sites, different contributions to the $\pi$ interactions could be identified and isolated. It includes not only the well known back donation and donation interactions, but also the intrafragment polarisation, which has not been considered in previous studies. This can be obtained through the use of the extended transition state method for energy decomposition analysis combined with the natural orbitals for chemical valence (ETS-NOCV) and the constrained space orbital variation (CSOV) analysis. The contributions vary with the position of the heteroatoms and the presence of exocyclic substituents; the donation/backdonation $\pi$ interactions between NHC and the coordination site can range between 2 and $61 \%$ of the total $\pi$ orbital interactions, while the rest is owed to intrafragment polarisation. Our results do not only contribute to the understanding of the electronic structure of NHC-based complexes, giving ways to improve their catalytic properties, but also provide comprehension on the modelisation methods used to study their donor-acceptor interactions.
\end{abstract}

Keywords: Density Functional Theory, Energy Decomposition Analysis, Natural Orbitals for Chemical Valence, donor-acceptor interactions

* Laboratoire de Chimie Moleculaire, Department of Chemistry, Ecole Polytechnique and CNRS, 91128 Palaiseau Cedex, France, elixabete.rezabal@polytechnique.edu

${ }^{\dagger}$ Laboratoire de Chimie Moleculaire, Department of Chemistry, Ecole Polytechnique and CNRS, 91128 Palaiseau Cedex, France, gilles.frison@polytechnique.edu 


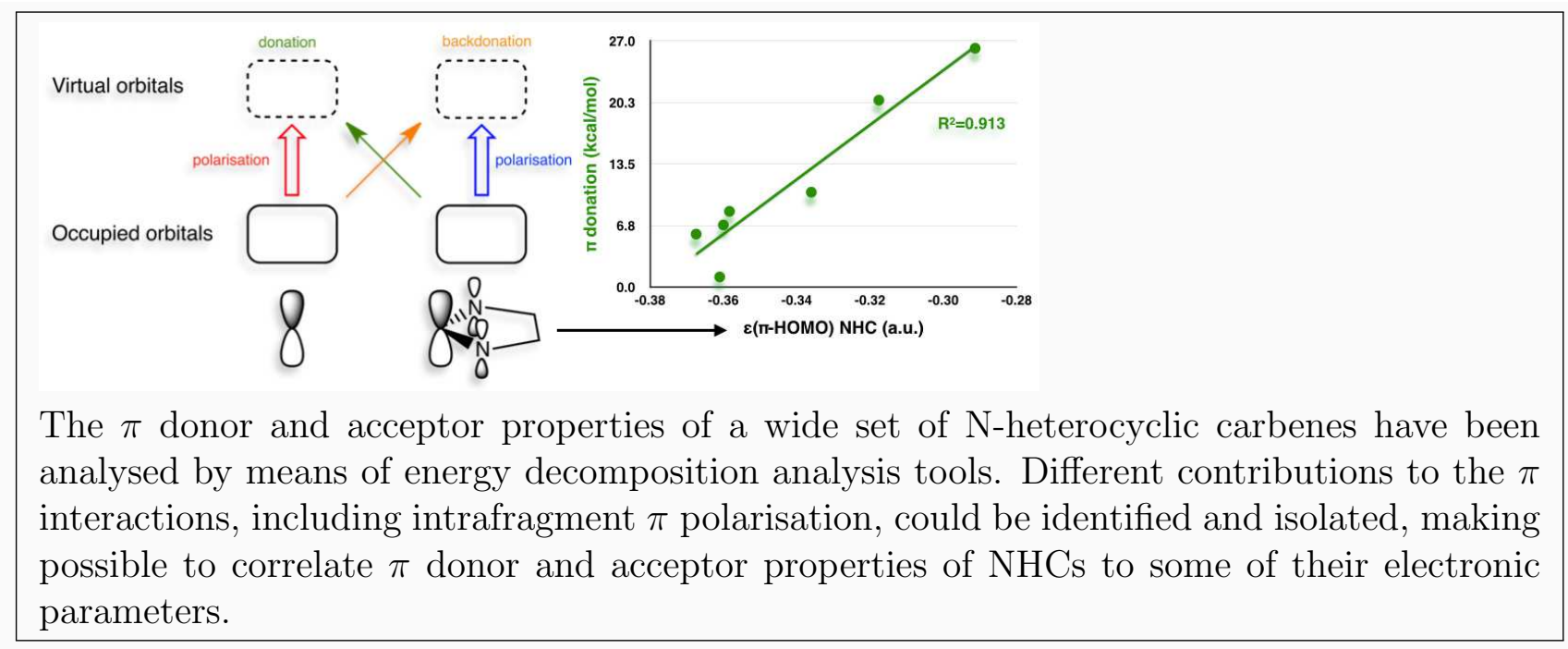




\section{INTRODUCTION}

N-heterocyclic carbenes (NHCs) have been successfully used in a variety of applications, as organocatalysts $^{1-3}$, or ligands to other species ${ }^{1,4-7}$, mainly based on their good $\sigma$ nucleophilic characteristics $^{8-11}$. In the last years, growing interest has been focused on their $\pi$ donor and acceptor properties ${ }^{12-14}$, generally as ligands to transition metals $(\mathrm{TMs})^{15-21}$, observing that NHCs present $\pi$ basicity or acidity, depending on the electronic structure of the metal ${ }^{22}$, and can vary the catalytic properties of the latter ${ }^{23}$. Works in the literature surprisingly show that even the formal $\mathrm{d}^{0} \mathrm{TMs}$ show a significant amount of $\pi$ backdonation, around $65 \%$ of the total $\pi$ bonding contribution. This amount increases with increasing the d-electron count and takes on values around $90 \%$ for $\mathrm{d}^{10}$ complexes $^{22}$. In other words, complexes with a low $\mathrm{d}$ electron count, show a contribution both from $\pi$ donation and from $\pi$ back donation; when species with more $\mathrm{d}$ electrons are considered, $\pi$ back bonding dominates the interaction of the $\pi$ orbitals of the NHC with the d orbitals of the metal center. This implies that the $\pi$ interactions modify the population of the d atomic orbitals in the metal center, which can backdonate electron density to the NHC even in formally $\mathrm{d}^{0} \mathrm{TM}$ complexes, or accept electron density in formally $\mathrm{d}^{10} \mathrm{TM}$ complexes. Consequently, the interaction between the partially filled $d$ orbital of the metallic fragment $\left(\mathrm{d}_{y z}\right.$ in the section (a) of Fig 1) and the partially filled $\pi$ orbital of the NHC gives rise to simultaneous donation and backdonation interactions. This makes difficult the separate study of donation and backdonation interactions, jeopardising to some extent the analysis of the $\pi$ donor and acceptor properties of NHCs. Different strategies have been used in the literature for estimating separately these two contributions, as the deletion of selected orbitals ${ }^{22,24}$, natural bond orbital (NBO) analysis $^{25}$, or the extended transition state (ETS) method for energy decomposition analysis

combined with the natural orbitals for chemical valence (NOCV) theory. ${ }^{26,27}$. Even if these procedures have significantly increased our understanding of the $\pi$ donor-acceptor interactions, the interpretation of the results is hindered by the limitations of these approaches and the complexity of the systems under study, which prevent to associate accurately each energetic term to a single contribution (vide infra).

In the quest of a more straightforward access to the NHC $\pi$ interactions, simpler coordi- 
nation sites establishing the $\pi$ interaction with atomic orbitals rather than with molecular orbitals are chosen in this work. The coordinating groups bear either empty or doubly occupied atomic orbitals, and therefore can be expected to undergo electron density transfer only in one direction, relying exclusively on NHC $\pi$ donor or acceptor properties.

Besides $\mathrm{H}^{+}$, which can not induce any $\pi$ donation or backdonation and has been chosen to give reference interaction energy values brought by the formation of a purely $\sigma$ bond, two different cationic coordination sites have been chosen: on one hand, the dihydro borenium cation, $\mathrm{BH}_{2}{ }^{+28}$ (see section (b) in Fig 1), with an occupied in plane $\mathrm{p}_{x}$ orbital and two empty $\mathrm{p}$ orbitals (out of plane, $\mathrm{p}_{y}$, and along the $\mathrm{C}_{\text {carbene-cation axis, }} \mathrm{p}_{z}$ ). In this case, the cation will behave as $\sigma$ acceptor in the $z$ axis and $\pi$ acceptor in the $y$ axis, enabling the $\pi$ donation from NHC. On the other hand, $\mathrm{F}^{+}$(see section (c) in Fig 1) includes an empty $\mathrm{p}_{z}$ orbital along the $\mathrm{C}_{\text {carbene }}$ bond axis and fully occupied $\mathrm{p}_{x}$ and $\mathrm{p}_{y}$ orbitals. It is expected that $\mathrm{F}^{+}$ will interact with the $\pi$ system of the NHC via backdonation from the doubly occupied p orbitals. While the three coordination sites are $\sigma$ acceptors, $\mathrm{BH}_{2}{ }^{+}$and $\mathrm{F}^{+}$are $\pi$ acceptor and donor, respectively, and as such, NHCs will behave as $\pi$ basic or acid moieties upon their binding. Similar description can be achieved for in plane $\pi$ interactions (noted $\pi_{/ /}$).

Most of the research published regarding the $\pi$ properties of NHCs has been devoted to imidazolylidenes and pyrimidinylidenes. Tuning the $\pi$ properties of NHCs by manipulating the position of the heteroatoms in the NHCs has yet to be considered in literature, even though, together with the exocyclic substituents, it has been observed to play a major role on these properties ${ }^{27,29}$.

In the present work, the role of endocyclic and exocyclic $\mathrm{N}$ atoms in the ring is considered (see Fig. 2). Different positions of the heteroatoms will be considered, giving rise to normal $(\mathbf{1}, \mathbf{2}$ and $\mathbf{3})$, remote $\left(\mathbf{5}^{30}, \mathbf{6}\right.$ and $\left.\mathbf{7}\right)$ and mesoionic $\left(\mathbf{4}^{31}, \mathbf{5 , 6}\right.$ and $\left.\mathbf{7}\right)$ NHCs.

\section{METHODOLOGY}

In this work, the bond between $\mathrm{H}^{+}, \mathrm{BH}_{2}{ }^{+}$and $\mathrm{F}^{+}$and the NHCs presented in Figure 2 is studied. M06HF/TZVP level, which has been shown to give the best results in terms of binding energy (see ESI) has been used for optimizations and frequency calculations (in 
order to ensuring the lack of imaginary modes) carried out in all the complexes, together with natural bond orbital (NBO) analysis ${ }^{32}$.

The interaction energy associated to the bond between the carbenes and the cations corresponds to the interaction of two fragments which posses the local equilibrium geometry of the final molecule, and which both have an electronic structure suitable for bond formation. A partition of this interaction in three terms, namely the electrostatic interaction $\Delta \mathrm{E}_{\text {elst }}$, the Pauli repulsion $\Delta \mathrm{E}_{\text {Pauli }}$ and the orbital interaction energy $\Delta \mathrm{E}_{o i}$, is performed by an energy decomposition analysis (EDA), following the well-known Morokuma-like energy partition of the bond using the ADF program (version 2013.01a) ${ }^{33}$.

$\Delta \mathrm{E}_{o i}$ can be further broken down into contributions from the orbital interactions within the various irreproducible representation of the overall symmetry group of the system (see Supporting Information).

The decomposition of the orbital interactions can be extended by performing additional constrained space orbital variation (CSOV) calculations ${ }^{34,35}$, as implemented in ADF. CSOV calculations permit to perform the bond decomposition analysis excluding selected virtual orbitals. Even if the change on the orbital space might lead to a slight deviation in the estimation of interaction energies, it is very valuable in order to understand the fundamentals of the NHC-coordination site interplay.

The extended transition state (ETS) ${ }^{36,37}$ method for energy decomposition analysis combined with the natural orbitals for chemical valence (NOCV) ${ }^{38-40}$ theory, computed at the same level of theory, is used as an alternative approach to decompose the $\Delta \mathrm{E}_{o i}$. Within this framework, it is possible to separate the orbital interactions between the NHC and their coordination site into contributions related to the deformation density due to the bonding. Each individual deformation density contribution is associated with an energy contribution to the total interaction energy. Complementary NOCVs with opposite sign and identical absolute energy eigenvalues can be grouped together to describe charge-transfer channels between the molecular fragments. Visualisation allows the assignment of these NOCV pairs to donating and backdonating processes and the identification of the participating fragment orbitals. 


\section{RESULTS AND DISCUSSION}

All the compounds studied present a planar ring, therefore resulting in symmetric complexes, with the exception of $\mathbf{5}$, whose exocyclic heteroatoms are pyramidalized. Carbenes $\mathbf{1}, \mathbf{6}$ and 7 present $\mathrm{C}_{2 v}$ symmetry, 2 belongs to the $\mathrm{C}_{2}$ symmetry group, and finally carbenes $\mathbf{3}$ and 4 bear $\mathrm{C}_{s}$ symmetry. These properties are maintained upon attachment to the different coordination sites (selected geometrical data is included in Table 1). As already observed for the protonated systems ${ }^{29}$, a widening of the $\mathrm{X}-\mathrm{C}_{\text {carbene }} \mathrm{Y}(\mathrm{X}, \mathrm{Y}=\mathrm{C}$ or $\mathrm{N})$ bond angle is observed, most notably for $\mathrm{F}^{+}$, followed by $\mathrm{H}^{+}$and finally $\mathrm{BH}_{2}{ }^{+}$(up to 11, 9 and 8 degrees, respectively). In agreement with previous observations, strong $\sigma$ acceptors lead to a rehybridization of the donor carbon atom and increase in the $\mathrm{X}-\mathrm{C}_{\text {carbene }}-\mathrm{Y}$ bond angle ${ }^{25}$. The electron density decrease on the $\mathrm{C}_{\text {carbene, }}$, the amount of which is connected to the electronegativity of the coordination site, leads to the enhancement of $\pi$ delocalisation, mainly from nitrogen atoms to $\mathrm{C}_{\text {carbene, }}$, and therefore, decrease of $\mathrm{C}_{\text {carbene }}-\mathrm{X}, \mathrm{Y}$ distance. $\mathrm{A}$ hypothetical $\pi$ donation from the cation would have the opposite effect, and competition between both donations would take place. In the studied complexes we find that $\mathrm{C}_{\text {carbene }}{ }^{-}$ $\mathrm{X}, \mathrm{Y}$ bonds are longest for $\mathrm{BH}_{2}{ }^{+}$, followed in decreasing order by $\mathrm{H}^{+}$and $\mathrm{F}^{+}$, as a result of the increasing $\sigma$ acceptor nature of the coordinating group. Even if we can expect a stronger $\sigma$ acceptor character of $\mathrm{F}^{+}$as compared to $\mathrm{H}^{+}$, the differences in $\mathrm{C}_{\text {carbene- }} \mathrm{X}, \mathrm{Y}$ distances are small, and in some cases, the ordering is reversed, due to the competition between the nitrogen atoms and $\mathrm{F}^{+}$to donate charge to $\mathrm{C}_{\text {carbene }}$.

Regarding the cation-NHC bond, $\mathrm{H}^{+}$binds the carbenes at a rather constant bond length of around $1.080 \AA . \mathrm{F}^{+}$forms bonds between $1.289 \AA$, in the case of NHC 2, and $1.338 \AA$ with the carbene $7 . \mathrm{BH}_{2}{ }^{+}$forms the longest bonds, between $1.520 \AA$ in $\mathrm{BH}_{2}{ }^{+}-7$ and 1.577 $\AA$ in $\mathrm{BH}_{2}{ }^{+}-2$, which correspond to the opposite trend compared to $\mathrm{F}^{+}$(vide infra).

Strong correlation is found between the cation interaction energy and the eigenvalues of the NHC $\sigma$ HOMO lone pair orbital (see Fig. S1), as already observed previously ${ }^{29,41,42}$. However, lower correlation is found for $\mathrm{BH}_{2}{ }^{+}-\mathrm{NHC}$ complexes $\left(\mathrm{R}^{2}=0.9012\right)$, as compared to that of $\mathrm{H}^{+}-\mathrm{NHC}\left(\mathrm{R}^{2}=0.9601\right)$ and $\mathrm{F}^{+}-\mathrm{NHC}\left(\mathrm{R}^{2}=0.9764\right)$ systems; $\mathrm{BH}_{2}{ }^{+}-\mathbf{5}$ seems particularly interesting on this regard, since it deviates significantly from linearity. This feature can 
be traced back to an important contribution of $\pi$ orbital interactions to the $\mathrm{BH}_{2}{ }^{+}$total interaction energy (vide infra).

Further insight on the bond nature is obtained by performing EDA analysis on these species, which permits the decomposition of the bond energy into Pauli repulsion $\left(\Delta \mathrm{E}_{\text {Pauli }}\right)$, electrostatic interaction $\left(\Delta \mathrm{E}_{\text {elst }}\right)$ and orbital interaction $\left(\Delta \mathrm{E}_{o i}\right)$ terms (Table S2). The composition of the bond is rather constant for each coordination site through the set of NHCs: $\mathrm{F}^{+}$relies mainly on orbital interactions (72.2\% in average) with few contribution of electrostatic interactions (around $27.8 \%)$, similarly to $\mathrm{H}^{+}(70.2 \%$ and $29.8 \%$, respectively) while $\mathrm{BH}_{2}{ }^{+}$depends equally on both (50.8\% and $49.2 \%$, respectively).

$\Delta \mathrm{E}_{\text {Pauli }}$ and $\Delta \mathrm{E}_{\text {elst }}$ contributions are strongest in the case of $\mathrm{F}^{+}$(see Table $\mathrm{S} 2$ ), due to its full p orbitals, and much lower for $\mathrm{BH}_{2}{ }^{+}$and $\mathrm{H}^{+}$, in decreasing order, due to the lower electron count. Overall, the electrostatic interactions and Pauli repulsions remain rather constant through the set of NHCs. As an exception, particularly low electrostatic contribution $(-159.3 \mathrm{kcal} / \mathrm{mol})$ and Pauli repulsion $(158.1 \mathrm{kcal} / \mathrm{mol})$ are observed for $\mathrm{BH}_{2}{ }^{+}$ 2, which correlates with the large bond length previously observed for this complex.

The sum of $\Delta \mathrm{E}_{\text {Pauli }}$ and $\Delta \mathrm{E}_{\text {elst }}$ gives the term $\Delta \mathrm{E}^{0}$ (see Table $\mathrm{S} 3$ ), which reflects the interaction between both fragments without electron transfer and orbital mixing. A large repulsive $\Delta \mathrm{E}^{0}$ is obtained for $\mathrm{F}^{+}$(between 252.7 and $292.4 \mathrm{kcal} / \mathrm{mol}$ ), arising from its fully occupied orbitals. Slightly negative or thermoneutral $\Delta \mathrm{E}^{0}$ values are obtained for $\mathrm{BH}_{2}{ }^{+}$, except for the case of carbenes 5 and $7(6.9 \mathrm{kcal} / \mathrm{mol}$ and $5.6 \mathrm{kcal} / \mathrm{mol}$, respectively), which can be related to the steric interactions between the cation and the exocyclic substituents. Finally, $\mathrm{H}^{+}$, due to its lack of Pauli repulsion, presents a $\Delta \mathrm{E}^{0}$ dominated by the attractive electrostatic forces.

Finally, very strong $\Delta \mathrm{E}_{o i}$ (between $710.2 \mathrm{kcal} / \mathrm{mol}$ and $731.1 \mathrm{kcal} / \mathrm{mol}$ ) are found for $\mathrm{F}^{+}$complexes. $\mathrm{H}^{+}$and $\mathrm{BH}_{2}{ }^{+}$form weaker orbital interactions $(182.5-228.3 \mathrm{kcal} / \mathrm{mol}$ and 167.1-231.7 kcal/mol, respectively); the broader affinity range denotes that the bond, in this case, is more sensitive to the nature of the NHC (see Table S2). This term will be further decomposed and analysed in the following section. 


\section{Orbital interaction decomposition and analysis}

$\Delta \mathrm{E}_{o i}$ can be decomposed into the irreducible representations of the symmetry group of the molecule by performing an EDA analysis. This permits to understand the nature of the bonds, and to identify the interactions that conform it. Due to the symmetry limitations on the chosen compounds, and for the sake of brevity, the complete analysis for NHC $\mathbf{1}$, which presents $\mathrm{C}_{2 v}$ symmetry, is presented here. The energy will be decomposed into $\mathrm{a}_{1}$, $\mathrm{a}_{2}, \mathrm{~b}_{1}$, and $\mathrm{b}_{2}$ contributions (see Table 2 ), which correspond to $\sigma, \delta, \pi$ and $\pi_{/ /}$interactions, respectively. As expected, the $\sigma$ interaction provides the largest part of the bond, being one order of magnitude stronger than $\pi$ and $\pi_{/ /}$interactions. $\pi$ and $\pi / /$ interactions are, in absolute values, strongest for $\mathrm{F}^{+}$, followed by $\mathrm{BH}_{2}{ }^{+}$and $\mathrm{H}^{+}$, but their contribution to the total orbital interaction is smaller; $\pi$ interactions represent only the $5.7 \%$ of the $\mathrm{F}^{+} \mathbf{- 1}$ bond, while this contribution rises to 13.8 and $19.8 \%$ with $\mathrm{H}^{+}$and $\mathrm{BH}_{2}{ }^{+}$, respectively. $\pi / /$ interactions, instead, are less significant for all the coordination sites and account for 3.8, 5.2 and $5.7 \%$, respectively. Finally, as expected, the contribution of $\delta$ interactions to the bond is negligible for any of the cations considered.

Surprisingly, interaction between $\mathrm{NHC}$ and $\mathrm{H}^{+}$imply $\pi$ (and to a lower extent $\pi_{/ /}$) contribution to the bonding, whereas only $\sigma$ interaction is expected. In order to identify the origin of these contributions, we perform CSOV calculations on these systems by deleting selected vacant orbitals. Deletion of the virtual orbitals of one fragment turns off all donation interactions into its orbitals, which allows to isolate and analyse the different possible interactions: (i) the $\pi$ donation takes place from the occupied $\pi$ orbitals of the NHC to the virtual $\pi$ orbitals of the coordination site, and can be estimated by deleting the virtual orbitals of NHC (right to left arrow in Fig 3); (ii) the $\pi$ backdonation occurs from the occupied orbitals of the cationic fragment to the virtual $\pi$ orbitals of the NHC and can be estimated by deleting the virtual orbitals of the cation (left to right dashed arrow in Fig 3); (iii) the polarisation is ascribed to the reorganisation inside each fragment (blank vertical

arrows in Fig 3). As it has already been discussed in the literature ${ }^{22,43}$, synergic and residual contributions to the orbital interaction energy arise from the different choices of variational space partitioning. Therefore, even if the following discussion based on CSOV data uses the 
numbers as obtained from the calculations, it must be remembered that these are roughly estimated and attention should rather be focused on the qualitative understanding of the different contributions to the $\pi$ bond.

For $\mathrm{H}^{+}-\mathbf{1}$, the deletion of empty $\mathrm{b}_{1}$ symmetry orbitals in the NHC depletes almost completely the $\mathrm{b}_{1}$ term $(2.5 \mathrm{kcal} / \mathrm{mol}$ in Table 3$)$ happening when all the empty orbitals are available $(25.1 \mathrm{kcal} / \mathrm{mol}$ ) (see Table 3$)$. This difference accounts for $22.6 \mathrm{kcal} / \mathrm{mol}$, and can be assigned to polarisation (or intra fragment electronic reorganization) within NHC, considering that $\mathrm{H}^{+}$has no electronic charge to backdonate to $\mathbf{1}$, or to polarise. The presence of a positively charged $\sigma$ acceptor results in the polarisation of the ring $\pi$ system towards the $\mathrm{C}_{\text {carbene }}$, which is included as $\pi$ interaction in EDA analysis.

$\mathrm{BH}_{2}{ }^{+}$bears empty $\mathrm{p}_{y}$ orbitals able of receiving $\pi$ electronic density from the NHC, and no occupied orbitals on the same symmetry. Therefore, deleting the $b_{1}$ symmetry orbitals of the carbene should lead to pure $\left(\mathrm{BH}_{2}{ }^{+} \leftarrow \mathrm{NHC}\right) \pi$ donation. This charge transfer is worth $13.3 \mathrm{kcal} / \mathrm{mol}$ for $\mathbf{1}$. The difference between this number and that accounting for all the empty $b_{1}$ orbitals in the system $(35.7 \mathrm{kcal} / \mathrm{mol})$ is, in fact, in good agreement with the intra fragment reorganisation previously estimated in $\mathrm{H}^{+}$complex $(22.5 \mathrm{kcal} / \mathrm{mol}$ vs $22.6 \mathrm{kcal} / \mathrm{mol}$ ). Consequently we can assume that the $\pi$-reorganisation within the NHC is similar for both $\mathrm{H}^{+}$and $\mathrm{BH}_{2}{ }^{+}$coordination, and that the $\pi$ donation from $\mathrm{NHC}$ to the $\mathrm{BH}_{2}{ }^{+}$ coordinating group accounts roughly for a third of the total $\pi$ contribution.

$\mathrm{F}^{+}$presents a doubly occupied $\mathrm{p}_{y}$ orbital which mainly prevents $\pi$ donation from the NHC to $\mathrm{F}^{+}$but can potentially donate charge to the NHC $\pi$ system. Deleting the empty $\mathrm{b}_{1}$ orbitals of the carbene results in a contribution of $12.8 \mathrm{kcal} / \mathrm{mol}$ in the $\mathrm{b}_{1}$ symmetry, significantly lower than the contribution for the complete system $(43.5 \mathrm{kcal} / \mathrm{mol})$. Following prior analysis for $\mathrm{H}^{+}$and $\mathrm{BH}_{2}{ }^{+}$, this means that NHC $\pi$ reorganisation and $\pi$ backdonation from $\mathrm{F}^{+}$contribute $30.7 \mathrm{kcal} / \mathrm{mol}(43.5-12.8)$ whereas polarisation within $\mathrm{F}^{+}$accounts for $12.8 \mathrm{kcal} / \mathrm{mol}$. Assuming that the intra fragment electronic reorganisation is similar to that obtained on $\mathrm{H}^{+}$species, we can estimate the net backdonation on $16.7 \mathrm{kcal} / \mathrm{mol}$.

Therefore, it is observed that, even if the $\pi$ interaction initially calculated for $\mathrm{F}^{+}$is significantly larger than that taking place with $\mathrm{BH}_{2}{ }^{+}$, the net donation to $\mathrm{BH}_{2}{ }^{+}(13.3 \mathrm{kcal} / \mathrm{mol})$ and backdonation from $\mathrm{F}^{+}(16.7 \mathrm{kcal} / \mathrm{mol})$ interactions are comparable. 
The occupied $\mathrm{p}_{y}$ orbital allow for $\mathrm{F}^{+}$to perform the similar calculation by deleting the empty $b_{1}$ symmetry orbitals of the cation. We then obtain throughout this second way a second value, $39.4 \mathrm{kcal} / \mathrm{mol}$, which should originate from the sum of the polarisation in the ring and the backdonation from the cationic moiety, whereas the polarisation within $\mathrm{F}^{+}$is now estimated in $4.1 \mathrm{kcal} / \mathrm{mol}(43.5-39.4 \mathrm{kcal} / \mathrm{mol})$. As indicated previously, the different number of orbitals used in the estimation of interaction energies in the CSOV method explains the deviation in the different values and limits the use of this tool to a qualitative approximation to the interactions. Nevertheless, this analysis indicates that the $\pi$ contribution to the bonding is not restrained to $\pi$ donation and $\pi$ backdonation, but also includes non negligeable $\pi$ polarisation within the fragments, which can be estimated from the $\pi$ contribution in the protonated complexes.

A similar analysis can be done in $\mathrm{b}_{2}$ symmetry, resulting in a internal in plane ring rearrangement of $8.5 \mathrm{kcal} / \mathrm{mol}(9.5-1.1)$, i.e. $14 \mathrm{kcal} / \mathrm{mol}$ below the value obtained in $\mathrm{b}_{1}$ symmetry, and negligible $\pi_{/ /}$donation from $\mathrm{NHC}$ to $\mathrm{BH}_{2}{ }^{+}$(see Table 3 ). Analysis of the CSOV values for $\mathrm{F}^{+}$shows a parallel behaviour to that in $\mathrm{b}_{1}$ symmetry. The sum of the $\pi_{/ /}$ backdonation from $\mathrm{F}^{+}$and the $\mathrm{NHC} \pi / /$ reorganisation is estimated between 16.4 and 25.3 $\mathrm{kcal} / \mathrm{mol}$, once again $14 \mathrm{kcal} / \mathrm{mol}$ below the values obtained in $\mathrm{b}_{1}$ symmetry $(30.7$ and 39.4 $\mathrm{kcal} / \mathrm{mol}$ ), indicating that $\pi$ and $\pi_{/ /}$backdonation have apparently the same intensity. Similarly, the $\pi_{/ /}$polarisation within $\mathrm{F}^{+}$amount to between 4.6 and $12.6 \mathrm{kcal} / \mathrm{mol}$, in agreement with the values obtained in the $\mathrm{b}_{1}$ symmetry $(4.1$ and $12.8 \mathrm{kcal} / \mathrm{mol})$.

\section{ETS-NOCV analysis}

The qualitative comprehension of the bond obtained thanks to the CSOV method will be used as a guide for a more quantitative understanding of the interactions, by means of the ETS-NOCV method. The latter will allow to obtain unbiased values for the different contributions and to extend the study to systems without symmetry.

NOCV analysis permits the visualisation of the electron density loss and gain in the system due to the bond formation and to calculate the energy contribution associated to it (see Fig 4). Similar NOCV shapes are found for all the NHCs included in this study (full analysis available in ESI), which can be assigned to recognisable $\sigma, \pi / /$ and $\pi$ interactions even 
in those systems without symmetry, allowing to extend the above analysis to all the NHCs, regardless their geometrical characteristics. Many NOCV pairs are found for each complex; in this work, we will consider only those related to an interaction energy of more than 1 $\mathrm{kcal} / \mathrm{mol}$. Comparing the results of the $\pi$ interactions to those obtained by EDA analysis (see Tables 2, S4 and S6), very satisfactory agreement is found between the $\pi$ interaction contributions of both partition schemes. As already observed in the EDA analysis, the $\sigma$ interactions are the most significant ones (see Table S4), and very similar $\sigma$ interactions are found for $\mathrm{H}^{+}$and $\mathrm{BH}_{2}{ }^{+}$(between 136.5 and $168.6 \mathrm{kcal} / \mathrm{mol}$ ), while $\mathrm{F}^{+}$results in much larger interactions (from 677.7 to $693.5 \mathrm{kcal} / \mathrm{mol}$ ).

Even if, as observed by EDA analysis, the bond is dominated by the $\sigma$ interaction, the $\Delta \mathrm{E}_{\pi}$ contribution is not negligible for any of the cations, supposing between 9 and $15 \%$ of the orbital interactions for $\mathrm{H}^{+}$complexes, $13-19 \%$ in the case of $\mathrm{BH}_{2}{ }^{+}, 5-6 \%$ in the case of $\mathrm{F}^{+}$. These numbers are not far from those found for TM-carbene bonds ${ }^{14,16,22}$, where the contribution of the $\pi$ system to the orbital interactions was estimated to be between 10 and $25 \%$.

The quantitative agreement between EDA and ETS-NOCV may be extended to the specific nature of the interactions. The NOCV analysis of the $\mathrm{H}^{+}$systems shows the $\pi$ manifold reorganisation in the carbene upon protonation. In addition to this reorganisation, $\mathrm{BH}_{2}{ }^{+}$and $\mathrm{F}^{+}$complexes bear interactions of the coordination site with the $\pi$ system of the ring (Figure 4).

$\pi$ NOCV pairs denote electron density loss (light grey surfaces on Fig. 4) mainly on the cation in the case of $\mathrm{F}^{+}$and on the carbene ring in the case of $\mathrm{BH}_{2}{ }^{+}$. Instead, the electron density gain (black surfaces on Fig. 4) is observed on the cation-NHC bond, for both coordination sites. Electron density gain is observed in $\mathrm{F}^{+}$, in perfect agreement with the CSOV analysis performed above, pointing out to a significant electronic rearrangement of the $\mathrm{F}^{+}$.

The $\pi_{/ /}$charge transfer occurs from the ring and cations to the $\mathrm{C}_{\text {carbene. }}$. When $\mathrm{F}^{+}$is considered as the coordination site, electron density loss is observed also in the divalent carbon atom and the electron density gain is extended to the $\mathrm{p}_{x}$ orbital of the coordination site. 
This picture is, overall, in consonance with the description of the bond provided by the CSOV analysis on $\mathbf{1}$, pointing out to the importance of the intrafragment reorganisation, and the separation of donation or backdonation interactions in the coordination sites chosen. Furthermore, it is observed that in $\mathrm{F}^{+}-\mathrm{NHC}$ complexes the $\mathrm{C}_{\text {carbene }}$ receives electron density from both the ring and the cation, what results in a mitigated reorganisation of the ring.

Considering the CSOV analysis performed above, the different contributions to the $\pi$ interaction can be extracted from the ETS-NOCV data. The intrafragment reorganisation of NHCs in presence of $\mathrm{BH}_{2}{ }^{+}$can be estimated to be equal to the $\pi$ contribution calculated in protonated systems. Furthermore, we can assume that the additional $\pi$ interactions found in $\mathrm{BH}_{2}{ }^{+}$correspond to the net $\left(\mathrm{BH}_{2}{ }^{+} \leftarrow \mathrm{NHC}\right) \pi$ donation. In the case of $\mathrm{F}^{+}$, this difference arises from the net $\left(\mathrm{F}^{+} \rightarrow \mathrm{NHC}\right) \pi$ backdonation plus a polarisation in $\mathrm{F}^{+}$. The polarisation within $\mathrm{F}^{+}$, which has been shown to be rather constant in the CSOV analysis, can be roughly estimated to be around $10 \mathrm{kcal} / \mathrm{mol}$ for the different NHC complexes, as shown by the difference between the $\pi$ interaction for $\mathrm{H}^{+}$(which should be inexistant) and $\mathrm{F}^{+}$in absence of virtual $\pi$ orbitals in the carbene. The bond energy partition based on this scheme is presented in Fig 5, and full data is provided in ESI.

The amount of energy retrieved from the ring electronic density redistribution towards the $\mathrm{C}_{\text {carbene }}$ (white in Fig 5) changes with the nature of the NHC (16.9 to $27.3 \mathrm{kcal} / \mathrm{mol}$ ). Nevertheless, it is the principal contribution to the total $\pi$ interaction in $\mathrm{BH}_{2}{ }^{+}$complexes, with the exception of $\mathbf{7}-\mathrm{BH}_{2}{ }^{+}$. Highest reorganisation energy is displayed by $\mathbf{1},(27.3 \mathrm{kcal} / \mathrm{mol})$, in which the $\mathrm{N}$ atoms in $\alpha$ position donate $\pi$ electron density to the divalent carbon atom. Instead, $\mathbf{2}$, also having two heteroatoms in $\alpha$, results in a weaker reorganisation $(21.5 \mathrm{kcal} / \mathrm{mol})$ due to the $\mathrm{sp}^{3}$ hybridised $\mathrm{C}$ atoms, which have worse donor ability than $\mathrm{sp}^{2}$ hybridised $\mathrm{C}$ atoms. $\mathrm{H}^{+} \mathbf{- 4}$, being identical to $\mathrm{H}^{+} \mathbf{- 1}$, presents a smaller polarisation $(19.9 \mathrm{kcal} / \mathrm{mol})$ since in this case the $\mathrm{C}_{\text {carbene }}$ has only one heteroatom in $\alpha$ position. The protonation of $\mathbf{5}$ also induces a significant reorganisation within the ring $(22.9 \mathrm{kcal} / \mathrm{mol})$, in which both endocyclic and exocyclic donor groups donate $\pi$ electron density to the divalent carbon atom. 7 , which maintains the exocyclic heteroatoms but not the endocyclic ones, undergoes a remarkably weaker reorganisation $(16.9 \mathrm{kcal} / \mathrm{mol})$. On the contrary, in the absence of the exocyclic heteroatoms, 6 shows a rearrangement of $19.2 \mathrm{kcal} / \mathrm{mol}$. Therefore, we can conclude that 
endocyclic $\mathrm{N}$ atoms polarise the $\pi$ system towards the $\mathrm{C}_{\text {carbene }}$ more efficiently. Finally, $\mathrm{H}^{+} \mathbf{- 3}$, being the same compound as $\mathrm{H}^{+} \mathbf{- 6}$, presents a stronger polarisation towards the coordination site $(24.1 \mathrm{kcal} / \mathrm{mol})$, since it has a $\alpha \mathrm{NH}-\mathrm{NH}$ moiety, in agreement with the $\mathrm{H}^{+} \mathbf{- 1} / \mathrm{H}^{+}-\mathbf{4}$ pair, suggesting that the $\alpha$ heteroatoms promote the delocalisation of the $\pi$ electrons towards the $\mathrm{C}_{\text {carbene }}$ more efficiently than $\beta$ heteroatoms.

Besides the ring reorganisation, in $\mathrm{BH}_{2}{ }^{+}$complexes we observe the net $\pi$ donation from the NHC, which varies between $1.1 \mathrm{kcal} / \mathrm{mol}$ and $26.2 \mathrm{kcal} / \mathrm{mol}$, accounting for the $4.9 \%$ and $60.8 \%$ of the $\pi$ interaction, respectively (see black bars in Fig 5). Our results indicate that mesoionic NHCs (4-7) induce larger $\pi$ donation than normal NHCs (1-3), in agreement with what has been described previously ${ }^{8}$. Furthermore, net donation towards the cation is highly favoured by the $\pi$ delocalisation of the lone pair of exocyclic $\mathrm{N}$ atoms in $\mathrm{BH}_{2}{ }^{+} \mathbf{5}$ and $\mathrm{BH}_{2}{ }^{+}-7$, accounting for 47.2 and $60.8 \%$ of the $\pi$ interaction, respectively. In this case, the endocyclic $\mathrm{N}$ atoms in 5 result in a weaker net $\pi$ donation $(20.5$ vs $26.2 \mathrm{kcal} / \mathrm{mol})$. This significantly large $\pi$ donation interactions are reflected in their total affinity towards $\mathrm{BH}_{2}{ }^{+}$, which is higher than initially suggested by the $\sigma$-HOMO eigenvalue (see Fig S1). Furthermore, it explains the short $\mathrm{C}_{\text {carbene-B }}$ bond length observed for both $\mathbf{5}$ and $\mathbf{7}$ (Table 1 and Figure S9).

The small influence of the -NH-NH- bridge on the $\pi$ donating capacity of $\mathbf{5}$ is confirmed by deleting the exocyclic substituents, which results in a net donation of only $8.3 \mathrm{kcal} / \mathrm{mol}$ in $\mathrm{BH}_{2}{ }^{+}$-6. By changing the coordination site to $\mathrm{BH}_{2}{ }^{+}-\mathbf{3}$, a similar yet slightly lower donation is observed $(5.8 \mathrm{kcal} / \mathrm{mol})$. Among those NHCs with no exocyclic substituents, the largest net donation occurs with $4(10.4 \mathrm{kcal} / \mathrm{mol})$. 1, with an interaction site with two $\alpha$ heteroatoms, presents a lower donation ability $(6.8 \mathrm{kcal} / \mathrm{mol})$. Therefore, even if the total $\pi$ interaction in 1 is higher than in 4 (34.1 vs $30.4 \mathrm{kcal} / \mathrm{mol})$, only $19.9 \%$ of it is net donation towards the cation, while it accounts for $34.4 \%$ in the latter. In this case, the electronegativity of the $\mathrm{CH}-\mathrm{CH}$ moiety in $\mathbf{1}$ improves the donation, as is evidenced by comparing it to $\mathbf{2}$ (1.1 $\mathrm{kcal} / \mathrm{mol})$.

In agreement with the literature ${ }^{27}$, no descriptor could be found for the total $\Delta \mathrm{E}_{\pi}$ energy. Interestingly, the donation energy correlates $\left(\mathrm{R}^{2}=0.913\right)$ with the $\pi$-HOMO eigenvalue of the bare NHC (see Figure 6); the higher the energy of the $\pi$-HOMO orbital, the better donor 
capacity is observed for the NHC. The donor capacity of the NHCs is also reflected in the bond distance with the cation, which decreases as higher is the donation energy (see Figure $\mathrm{S} 9)$.

A similar partition can be done also in $\mathrm{F}^{+}$-NHC complexes, keeping in mind that the NOCV pairs show a smaller reorganisation within the NHCs as compared to $\mathrm{H}^{+}$and $\mathrm{BH}_{2}{ }^{+}$ bound complexes (see Figures 4 and S1-8 in ESI), and therefore, an overestimation of the reorganisation contribution in this case must be assumed. Similarly, the $10 \mathrm{kcal} / \mathrm{mol}$ polarisation within the coordination site is probably overestimated by the CSOV analysis. This uncertainty is denoted by error bars in Figure 4.

Nevertheless, it can be observed that the electronic reorganisation in the fragments is a noticeable contribution in the total $\pi$ interaction. The net backdonation provides between 8.3 and $26.7 \%$ of the $\pi$ interaction, while the rest is due to intrafragment reorganisation. The absence of exocyclic $\left(6-\mathrm{F}^{+}\right)$or endocyclic $\left(7-\mathrm{F}^{+}\right) \mathrm{N}$ atoms increases the backdonation to 8.9 and $8.2 \mathrm{kcal} / \mathrm{mol}$, respectively, compared to the low $(3.0 \mathrm{kcal} / \mathrm{mol})$ back donation obtained for 5. Changing the binding site from $6-\mathrm{F}^{+}$to $3-\mathrm{F}^{+}$results yet in a better backdonation

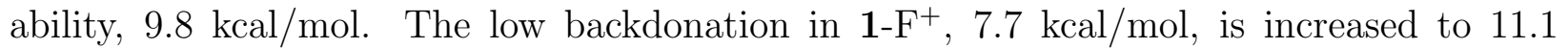
$\mathrm{kcal} / \mathrm{mol}$ by the presence of the $\mathrm{CH}_{2}-\mathrm{CH}_{2}$ moiety in the ring $\left(2-\mathrm{F}^{+}\right)$, and by the change in the coordination site to $4-\mathrm{F}^{+}(10.9 \mathrm{kcal} / \mathrm{mol})$.

\section{CONCLUSIONS}

Besides the crucial role of $\sigma$ interactions in the total orbital interactions, we have observed for various NHCs that the role of $\pi$ interactions is very significant even in main group element coordination sites. Overall, the contribution of $\pi$ interactions to the bond is comparable to that found in TM fragments in the literature ${ }^{22,27}$.

The $\pi$ interactions can be decomposed into intrafragment reorganisation, and backdonation or donation contributions between the fragments. In particular, we have found that the $\pi$ polarisation within the NHC ring is a significant or even the main contribution (up to $90 \%$ ) of the computed $\pi$ interaction. Consequently, we could postulate that decomposing the interaction only in donation/backdonation contributions results in their unreliable 
estimation. The scheme usually employed to analyse the TM-NHC $\pi$ interactions might overestimate both the donation from the NHC and the back donation to the NHC, since it hides a fundamental part of the $\pi$ contributions, namely the fragment reorganisation.

From this energetic decomposition, it has been observed that MICs show the best donor properties, while normal NHCs have remarkable acceptor properties. Furthermore, it becomes possible for the first time to nicely correlate for example the $\pi$ donation with the $\pi$ HOMO eigenvalue of the bare NHC, or the cation-NHC bond length.

We believe that the study presented here will contribute significantly not only to the intimate comprehension of the intrinsic $\pi$ bonding characteristics of NHCs, but also to the understanding and perfectioning of the computational tools to study metal-ligand interactions. This could facilitate the analysis of experimental quantification of the NHCs electronic

properties $^{44-46}$, as well as the design of catalytic TM-NHC complexes with the desirable electronic properties.

\section{ACKNOWLEDGMENTS}

This work was granted access to the HPC resources of CINES under the allocation x2014086894 made by GENCI (Grand Equipement National de Calcul Intensif). 


\section{References}

1. N. Marion, S. Diez-Gonzalez, and S. Nolan, Angew. Chem. Int. Ed. 46, 2988 (2007).

2. D. Enders, O. Niemeier, and A. Henseler, Chem. Rev. 107, 5606 (2007).

3. O. Holloczki, Z. Kelemen, and L. Nyulaszi, J. Org. Chem. 77, 6014 (2012).

4. F. Hahn and M. Jahnke, Angew. Chem. Int. Ed. 47, 3122 (2008).

5. D. P. Curran, A. Solovyev, M. Makhlouf, L. Fensterbank, M. Malacria, and E. Lacote, Angew. Chem. Int. Ed. 50, 10294 (2011).

6. W. A. Herrmann, Angew. Chem. Int. Ed. 41, 1290 (2002).

7. S. Bellemin-Laponnaz and S. Dagorne, Chem. Rev. 114, 8747 (2014).

8. O. Schuster, L. Yang, H. G. Raubenheimer, and M. Albrecht, Chem. Rev. 109, 3445 (2009).

9. R. H. Crabtree, Coord. Chem. Rev. 257, 755 (2013).

10. M. N. Hopkinson, C. Richter, M. Schedler, and F. Glorius, Nature 510, 485 (2014).

11. D. G. Gusev, Organometallics 28, 6458 (2009).

12. D. Martin, N. Lassauque, B. Donnadieu, and G. Bertrand, Angew. Chem. Int. Ed. 51, 6172 (2012).

13. A. Kausamo, H. M. Tuononen, K. E. Krahulic, and R. Roesler, Inorg. Chem. 47, 1145 (2008).

14. D. Nemcsok, K. Wichmann, and G. Frenking, Organometallics 23, 3640 (2004).

15. X. Hu, Y. Tang, P. Gantzel, and K. Meyer, Organometallics 22, 612 (2003).

16. X. Hu, I. Castro-Rodriguez, K. Olsen, and K. Meyer, Organometallics 23, 755 (2004).

17. R. Dorta, E. D. Stevens, N. M. Scott, C. Costabile, L. Cavallo, C. D. Hoff, and S. P. Nolan, J. Am. Chem. Soc. 127, 2485 (2005).

18. S. Fantasia, J. L. Petersen, H. Jacobsen, L. Cavallo, and S. P. Nolan, Organometallics 26, 5880 (2007).

19. D. J. Nelson and S. P. Nolan, Chem. Soc. Rev. 42, 6723 (2013).

20. D. M. Khramov, V. M. Lynch, and C. W. Bielawski, Organometallics 26, 6042 (2007).

21. D. Marchione, L. Belpassi, G. Bistoni, A. Macchioni, F. Tarantelli, and D. Zuccaccia, Organometallics 33, 4200 (2014). 
22. H. Jacobsen, A. Correa, C. Costabile, and L. Cavallo, J. Organomet. Chem. 691, 4350 (2006).

23. M. Alcarazo, T. Stork, A. Anoop, W. Thiel, and A. Fürstner, Angew. Chem. Int. Ed. 49, 2542 (2010).

24. R. Tonner, G. Heydenrych, and G. Frenking, Chem. Asian. J. 2, 1555 (2007).

25. A. Comas-Vives and J. N. Harvey, Eur. J. Inorg. Chem. 2011, 5025 (2011).

26. M. Srebro and A. Michalak, Inorg. Chem. 48, 5361 (2009).

27. J. C. Bernhammer, G. Frison, and H. V. Huynh, Chem. Eur. J. 19, 12892 (2013).

28. B. Ines, M. Patil, J. Carreras, R. Goddard, W. Thiel, and M. Alcarazo, Angew. Chem. Int. Ed. 50, 8400 (2011).

29. H. V. Huynh and G. Frison, J. Org. Chem. 78, 328 (2013).

30. C. Dyker, V. Lavallo, B. Donnadieu, and G. Bertrand, Angew. Chem. Int. Ed. 47, 3206 (2008).

31. E. Aldeco-Perez, A. J. Rosenthal, B. Donnadieu, P. Parameswaran, G. Frenking, and G. Bertrand, Science 326, 556 (2009).

32. E. D. Glendening, A. E. Reed, J. E. Carpenter, and F. Weinhold, Nbo version 3.1.

33. G. T. E. Velde, F. M. Bickelhaupt, E. J. Baerends, C. F. Guerra, and S. Gisbergen, J. Comput. Chem. 22, 931 (2001).

34. P. S. Bagus, K. Hermann, and C. W. Bauschlicher, J. Chem. Phys. 80, 4378 (1984).

35. P. S. Bagus and F. Illas, J. Chem. Phys. 96, 8962 (1992).

36. T. Ziegler and A. Rauk, Inorg. Chem. 18, 1558 (1979).

37. T. Ziegler and A. Rauk, Inorg. Chem. 18, 1755 (1979).

38. M. P. Mitoraj, A. Michalak, and T. Ziegler, J. Chem. Theory Comput. 5, 962 (2009).

39. M. Mitoraj and A. Michalak, J. Mol. Model. 13, 347 (2007).

40. A. Michalak and M. Mitoraj, J. Phys. Chem. A 112, 1933 (2008).

41. R. Tonner, G. Heydenrych, and G. Frenking, ChemPhysChem 9, 1474 (2008).

42. S. Klein, R. Tonner, and G. Frenking, Chem. Eur. J. 16, 10160 (2010).

43. H. B. Kraatz, H. Jacobsen, T. Ziegler, and P. M. Boorman, Organometallics 12, 76 (1993). 
44. R. R. Rodrigues, C. L. Dorsey, C. A. Arceneaux, and T. W. Hudnall, Chem. Commun. 50, 162 (2013).

45. O. Back, M. Henry-Ellinger, C. D. Martin, D. Martin, and G. Bertrand, Angew. Chem. Int. Ed. 52, 2939 (2013).

46. A. Liske, K. Verlinden, H. Buhl, K. Schaper, and C. Ganter, Organometallics 32, 5269 (2013). 


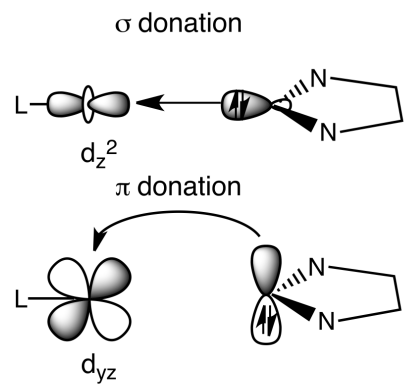

$\pi$ backdonation
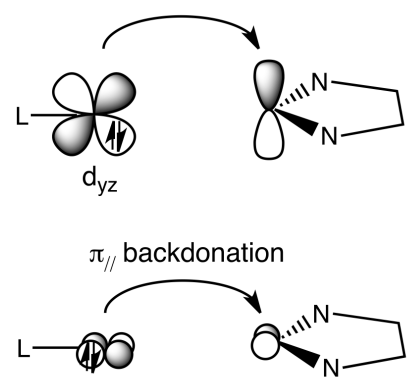

$\mathrm{d}_{\mathrm{xz}}$

TM
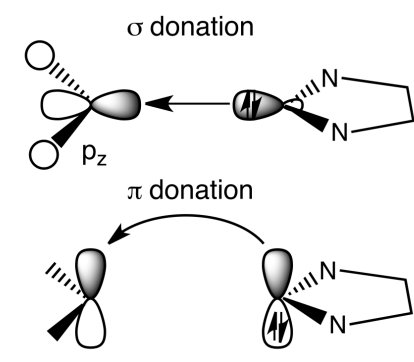

$p_{y}$

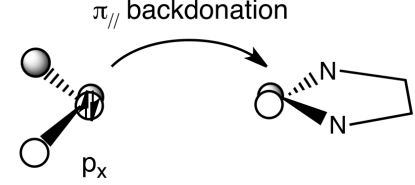

$\mathrm{BH}^{+}$

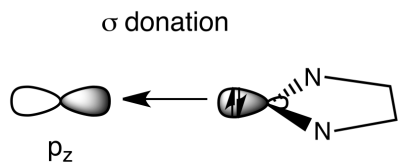

$p_{z}$

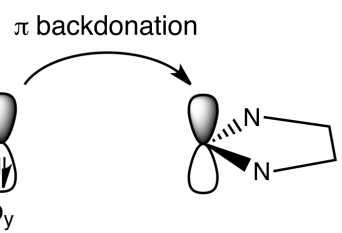

$\pi_{/ /}$backdonation

(i)

$p_{x}$

$\mathrm{F}^{+} \quad \mathrm{NHC}$

(c)

Figure 1: Schematic representation of the interactions taking place between a NHC and a metallic fragment (a), $\mathrm{BH}_{2}^{+}(\mathrm{b})$ and $\mathrm{F}^{+}(\mathrm{c})$.<smiles>c1cc[nH]c1</smiles><smiles>C1CCNC1</smiles><smiles>C1=CN[CH+]1</smiles><smiles></smiles><smiles>NC12CCC(N)(C1)C2</smiles>

Figure 2: NHCs studied in this work. 


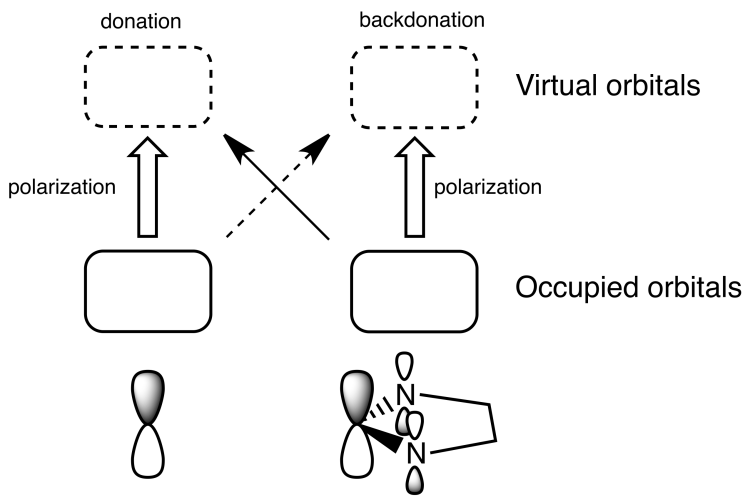

Figure 3: Schematic representation of the different contributions to the $\pi$ interaction between the coordination site and the NHC

(a)

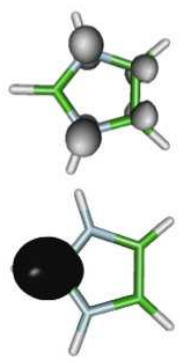

$\pi$

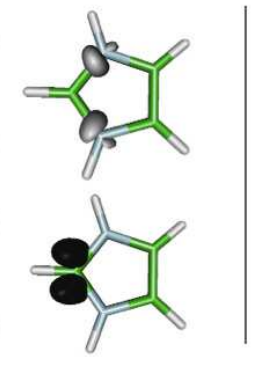

$\pi / /$
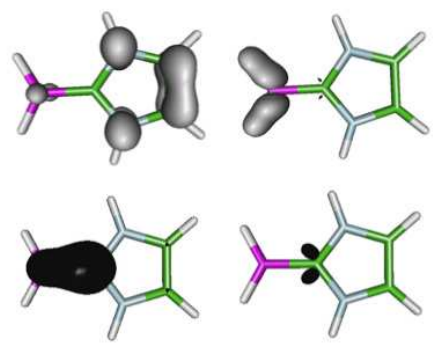

$\pi$

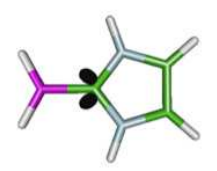

$\pi / /$
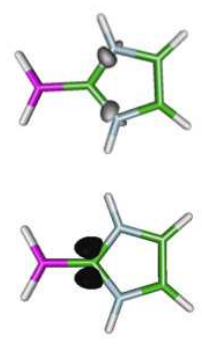

$\pi / /$

(c)
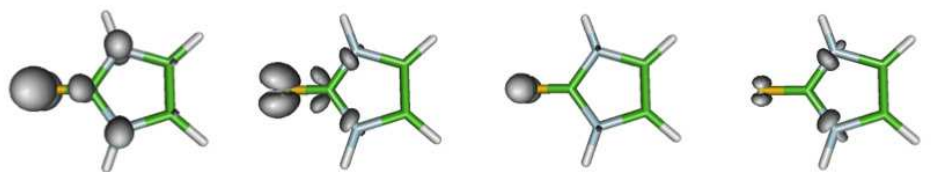

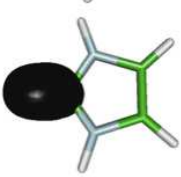

$\pi$

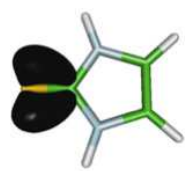

$\pi / /$

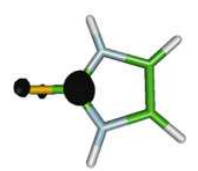

$\pi$

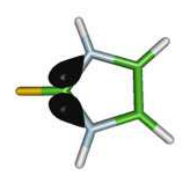

$\pi / /$

Figure 4: Contours of deformation density contributions for the $\pi$ and $\pi_{/ /}$symmetry pairs of interacting orbitals for $\mathrm{H}^{+}-\mathbf{1}$ (a), $\mathrm{BH}_{2}{ }^{+}-\mathbf{1}$ (b) and $\mathrm{F}^{+}-\mathbf{1}$ (c) complexes. Light grey surfaces denote loss of electron density, black surfaces denote gain of electron density. Isosurface value: 0.004 a.u. 


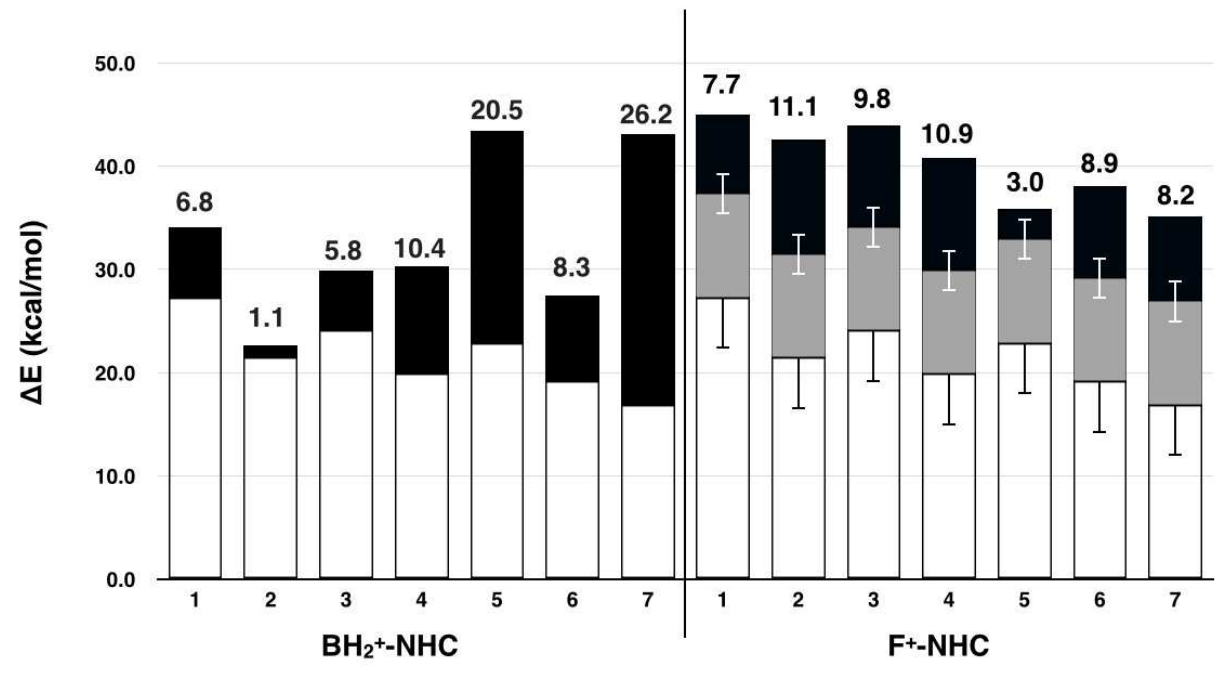

Figure 5: Stabilization energies, in $\mathrm{kcal} / \mathrm{mol}$, of the $\pi$ symmetry pairs of interacting orbitals of each NHC bound to $\mathrm{BH}_{2}{ }^{+}$(left) and $\mathrm{F}^{+}$(right). White stands for the ring reorganisation energy, black for the donation and retrodonation, and grey for the polarisation within $\mathrm{F}^{+}$. The donation $\left(\mathrm{BH}_{2}{ }^{+} \leftarrow \mathrm{NHC}\right)$ or backdonation $\left(\mathrm{F}^{+} \rightarrow \mathrm{NHC}\right)$ energies are included for each complex. The uncertainty related to the polarisation within $\mathrm{F}^{+}$and $\mathrm{NHC}$ in $\mathrm{F}^{+}-\mathrm{NHC}$ complexes is indicated by error bars. 


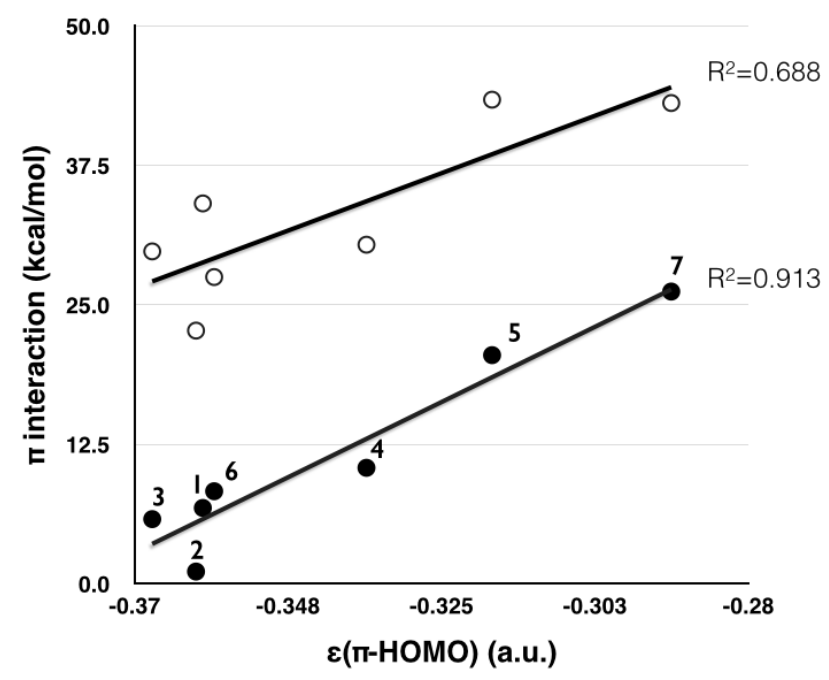

Figure 6: Correlation between the $\left(\mathrm{BH}_{2}{ }^{+} \leftarrow \mathrm{NHC}\right)$ donation interaction for $\mathrm{BH}_{2}{ }^{+}-\mathrm{NHC}$ complexes and the $\pi$-HOMO eigenvalue of the bare NHC. Empty circles denote total $\Delta \mathrm{E}_{\pi}$ interactions, solid circles stand for $\left(\mathrm{BH}_{2}{ }^{+} \leftarrow \mathrm{NHC}\right)$ donation energy. 


\begin{tabular}{|c|c|c|c|c|c|c|c|c|c|c|c|c|c|c|c|}
\hline & \multicolumn{3}{|c|}{$\mathrm{NHC}$} & \multicolumn{4}{|c|}{$\mathrm{NHC}_{-} \mathrm{BH}_{2}{ }^{+}$} & \multicolumn{4}{|c|}{$\mathrm{NHC}_{-} \mathrm{H}^{+}$} & \multicolumn{4}{|c|}{$\mathrm{NHC}_{-} \mathrm{F}^{+}$} \\
\hline & $\mathrm{X}-\mathrm{C}_{c}-\mathrm{Y}$ & $\mathrm{C}_{c}-\mathbf{N}$ & $\mathrm{C}_{c}-\mathrm{C}$ & $\mathrm{C}_{c}-\mathrm{L}$ & $\mathrm{X}-\mathrm{C}_{c}-\mathrm{Y}$ & $\mathrm{C}_{c}-\mathrm{N}$ & $\mathrm{C}_{c}-\mathrm{C}$ & $\mathrm{C}_{c}-\mathrm{L}$ & $\mathrm{X}-\mathrm{C}_{c}-\mathrm{Y}$ & $\mathbf{C}_{c}-\mathbf{N}$ & $\mathrm{C}_{c}-\mathrm{C}$ & $\mathrm{C}_{c}-\mathrm{L}$ & $\mathrm{X}-\mathrm{C}_{c}-\mathrm{Y}$ & $\mathrm{C}_{c}-\mathrm{N}$ & $\mathrm{C}_{c}-\mathrm{C}$ \\
\hline 1 & 100.6 & 1.356 & - & 1.535 & 105.7 & 1.339 & - & 1.076 & 107.1 & 1.330 & - & 1.274 & 109.3 & 1.322 & - \\
\hline 2 & 103.7 & 1.344 & - & 1.577 & 111.5 & 1.311 & - & 1.083 & 112.8 & 1.306 & - & 1.273 & 114.7 & 1.305 & - \\
\hline 3 & 101.7 & 1.325 & 1.440 & 1.549 & 107.3 & 1.336 & 1.392 & 1.079 & 108.2 & 1.335 & 1.382 & 1.280 & 109.7 & 1.340 & 1.380 \\
\hline 4 & 100.5 & 1.390 & 1.383 & 1.539 & 104.5 & 1.395 & 1.365 & 1.076 & 106.4 & 1.373 & 1.358 & 1.285 & 108.2 & 1.374 & 1.352 \\
\hline 5 & 98.6 & - & 1.385 & 1.508 & 104.1 & - & 1.410 & 1.077 & 106.0 & - & 1.387 & 1.317 & 108.2 & - & 1.383 \\
\hline 6 & 101.4 & - & 1.393 & 1.535 & 105.6 & - & 1.393 & 1.076 & 105.9 & - & 1.387 & 1.295 & 107.4 & - & 1.384 \\
\hline 7 & 99.2 & - & 1.387 & 1.490 & 105.7 & - & 1.407 & 1.078 & 105.8 & - & 1.389 & 1.320 & 110.5 & - & 1.379 \\
\hline
\end{tabular}

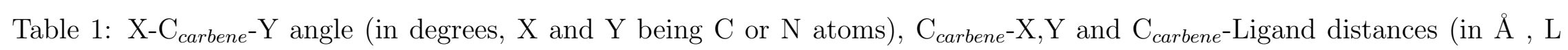
being B, H and F atoms) for all the systems studied, computed at the M06HF/TZVP level. 


\begin{tabular}{lcccc} 
& $\mathbf{a}_{1}$ & $\mathbf{a}_{2}$ & $\mathbf{b}_{1}$ & $\mathbf{b}_{2}$ \\
\hline $\mathrm{H}^{+}$ & $-145.6(\% 79.8)$ & $-2.1(\% 1.2)$ & $-25.1(\% 13.8)$ & $-9.5(\% 5.2)$ \\
$\mathrm{BH}_{2}{ }^{+}$ & $-133.6(\% 73.9)$ & $-1.3(\% 0.7)$ & $-35.8(\% 19.8)$ & $-10.3(\% 5.7)$ \\
$\mathrm{F}^{+}$ & $-684.9(\% 90.2)$ & $-2.2(\% 0.3)$ & $-43.5(\% 5.7)$ & $-29.0(\% 3.8)$ \\
\hline
\end{tabular}

Table 2: Decomposition of $\Delta \mathrm{E}_{o i}$ (in $\mathrm{kcal} / \mathrm{mol}$ ) between the NHC 1 and the cationic groups.

\begin{tabular}{lcc|cc|cc} 
& \multicolumn{2}{c}{$\mathrm{H}^{+}$} & \multicolumn{2}{c}{$\mathrm{BH}_{2}+$} & \multicolumn{2}{c}{$\mathrm{F}^{+}$} \\
\hline & $\mathbf{b}_{1}$ & $\mathbf{b}_{2}$ & $\mathbf{b}_{1}$ & $\mathbf{b}_{2}$ & $\mathbf{b}_{1}$ & $\mathbf{b}_{2}$ \\
\hline $\mathrm{NHC}_{1}$ & -2.5 & -12.8 & -13.3 & -13.2 & -12.8 & -32.5 \\
Cationic group $\mathrm{b}_{1}$ & & & & & -39.4 & -29.4 \\
\hline $\mathrm{NHC}_{2}$ & -27.9 & -1.1 & -37.5 & -2.9 & -47.1 & -12.6 \\
Cationic group $\mathrm{b}_{2}$ & & & -43.3 & -10.2 & -34.9 & -25.3 \\
\hline No deleted orbitals & -25.1 & -9.5 & -35.7 & -10.3 & -43.5 & -29.0 \\
\hline
\end{tabular}

Table 3: CSOV analysis of the contribution of the symmetry groups $\mathrm{b}_{1}$ and $\mathrm{b}_{2}$ on the $\Delta \mathrm{E}_{o i}$ of carbene 1, in kcal/mol. The first column specifies the virtual orbitals that have been deleted for the given fragment. 